\title{
Seepage test by HCA for remolded kaolin
}

\author{
Jian Zhou ${ }^{1,2}{ }^{*}$, Jie Xu ${ }^{1,2}$, Linghui Luo ${ }^{1,2}$, Lianggui $\mathrm{Yu}^{1,2}$, and Xiaonan Gong ${ }^{1,2}$ \\ ${ }^{1}$ Zhejiang University, Research Center of Coastal and Urban Geotechnical Engineering, 310058 Hangzhou, China \\ ${ }^{2}$ Engineering Research Center of Urban Underground Development of Zhejiang Province, 310058 Hangzhou, China
}

\begin{abstract}
Permeability is an import character of soil, especially in excavation and tunnelling. Hollow cylindrical apparatus (HCA) is often used to determine soil anisotropy, particularly soil strength and stiffness under different directions of major principal stress, so complex stress paths can be simulated and the corresponding soil properties can be examined. It can also be used to determine the permeability coefficient if a special mode is added, therefore the seepage test can be expected. Owing to no seepage test has been conducted by HCA before, the complete procedure of HCA seepage tests after static and dynamic loading are respectively studied. And the seepage stability stage is discussed since only data in this stage are valid and reliable for permeability calculation. The results show that:1) when the difference in average permeability coefficient within unit time ( 3600 seconds) less than $2 \%$ in $24 \mathrm{~h}$, it is reliable to take the average permeability coefficient in this period as the ultimate permeability in static seepage test; 2 ) for dynamic test, if the average permeability in 3600 seconds varies with $5 \%$ in $24 \mathrm{~h}$, the average permeability coefficient in this period can be taken as the ultimate value. Research in this paper provides a solid foundation for HCA seepage test under complex stress paths.
\end{abstract}

\section{Introduction}

Since the concept of "permeability coefficient" was published in the 1850s [1], many scholars have devoted themselves to study the influencing factors and measuring methods of permeability coefficient. But different test methods and standards will lead to different test results [2]. Particularly for cohesive soils, the permeability coefficient is comparatively low and small difference in measurement will lead to large variation in results. One of the major difficulties in the seepage test is the sidewall leakage [3]. In response to this difficulty, scholars are committed to reduce the errors by smearing water proof materials and adding O-rings [4-5], but there is no significant effect. From this perspective, permeability from triaxial permeameter is much better since the confining pressure pushing the latex film closely attached to the soil surface, which makes the elimination of sidewall leakage possible [6].

While the triaxial permeameter is not ideal. First, there is no axial strain sensor in most triaxial permeameters [6-7], so the radial strain and axial strain cannot well represent the real responses, which causes large errors in results and standards. Second, another representative triaxial permeameter is GDS advanced consolidation instrument, which is a modified instrument based on the ROWE-cell. The biggest disadvantage of GDS advanced consolidation instrument is that there is no latex film between the outer wall of the sample and the inner wall of the container, which causes sidewall leakage [8]. Third, the triaxial permeameter can only perform seepage test after static loading, and is incapable of dynamic loading study.
Nowadays dynamic problems are broadly involved in practical engineering and need more concern. Hence new equipment for better accuracy and complex stress state is more attractive.

Complex stress paths can be simulated by hollow cylindrical apparatus (i.e. HCA) [9], meanwhile HCA has axial strain transducer, so seepage test is highly expected. If simply think of the axial strain transducer as the biggest advantage of HCA, the value of developing the seepage mode in HCA will be greatly reduced. In fact, after the dynamic loading, the void ratio and the pore distribution of the soil changed significantly, which would change the permeability coefficient [10]. So the biggest advantage of seepage test by HCA is that the law of permeability coefficient after dynamic load and the principle behind the law can be explored.

After adding a new seepage mode in ZJU-HCA, the permeability test by HCA is studied. In order to get accurate and reliable results, stable stage in seepage test is of great importance, since only data in stable stage can be used for calculation. This paper focuses on stable stage study in static and dynamic permeability test and aims to provide a theoretical basis for HCA permeability test and dynamic loading effect on permeability.

\section{HCA seepage test research}

\subsection{Sample preparation and test program}

Soil properties such as clay content and organic content have great impact on the permeability coefficient [11]. In

\footnotetext{
* Corresponding author: zjelim@zju.edu.cn
} 
order to ensure the uniformity and comparability, Malaysia kaolin was used in this study since this soil is relatively stable, and the physical parameters of Malaysian kaolin are shown in Table 1. First mix the soil and water with the mass ratio of $1: 2$ by a high-power blender, and pore the mud into the plexiglass bucket of $180 \mathrm{~mm} \times 650 \mathrm{~mm}$ (diameter $\times$ height). Intermittently vibrate the bucket to vent the air so less pores exist. After resting for 24 hours, move the plexiglass bucket to airpressure consolidation instrument, and consolidate at $90 \mathrm{kPa}$. After the consolidation is completed, the water content is $56 \%$.

Table 1. Test program

\begin{tabular}{ccccc}
\hline $\begin{array}{c}\mathrm{SiO}_{2} / \\
\%\end{array}$ & $\begin{array}{c}\mathrm{Al}_{2} \mathrm{O}_{3} / \\
\%\end{array}$ & $\begin{array}{c}\text { specific } \\
\text { gravity }\end{array}$ & $\begin{array}{r}\text { Liquid } \\
\text { limit/\% }\end{array}$ & $\begin{array}{c}\text { Plastic } \\
\text { limit/\% }\end{array}$ \\
\hline $47-53$ & $32-38$ & 2.68 & 65.35 & 40.04 \\
\hline
\end{tabular}

The purpose of this text is to explore how to judge the seepage stable stage during HCA seepage test, so only two types of test were designed to explore the complete procedure and seepage stable stage, as shown in Table 2.

Table 2. Test program

\begin{tabular}{c|ccc}
\hline Number & $\begin{array}{c}\text { Sample } \\
\text { number }\end{array}$ & Loading types & Factors \\
\hline 1 & S1i10 & Static loading & \\
\hline 2 & S2i10 & $\begin{array}{c}\text { Dynamic } \\
\text { loading }\end{array}$ & $\begin{array}{c}\text { Frequency=1.0; } \\
\text { Cycles }=10000 .\end{array}$ \\
\hline
\end{tabular}

Note: "S1" represents the seepage test after static loading; "S2" represents the seepage test after dynamic loading. "i10"represents that the hydraulic gradient is 10 , which demonstrated to be suitable for this kind of test [12]. "Dynamic loading" refers to Hao's research, and the heart-shaped stress path is used to simulate traffic loads [9].

\subsection{Test procedure}

The remoulded kaolin was cut into hollow cylinder sample of $200 \mathrm{~mm} \times 100 \mathrm{~mm} \times 60 \mathrm{~mm}$ by a special sample kit, then the sample was installed in ZJU-HCA. Test procedure is as follows:

(1) Saturation: set back pressure $100 \mathrm{kPa}$, the external and internal pressure $105 \mathrm{kPa}$, then saturate the sample until B value greater than 0.98 .

(2) Consolidation: after saturation, consolidate the specimen at effective stress $100 \mathrm{kPa}$ with double-drainage until the drainage volume of back pressure controller less than $100 \mathrm{~mm}^{3}$ per $3600 \mathrm{~s}$.

(3) Seepage test: recalculate the sample diameter and height and reconstruct the test file. Set the base pressure to $100+\Delta u / 2 \mathrm{kPa}$ and the back pressure to $100 \mathrm{~s} \Delta u / 2$ $\mathrm{kPa}$ according to the designed hydraulic gradient, where $\Delta u$ is the pressure difference between the base pressure controller and back pressure controller (the seepage direction is from the bottom to top). Conduct seepage test under stress mode, during which the axial force maintained zero.

(4) Reconsolidation: consolidate the sample again. This step is to eliminate the uneven distribution of pore water pressure along the sample during seepage stage. Note that if seepage test conducted under strain mode this reconsolidation is very important otherwise the existing initial axial force will violate the predesigned path. This step is the same as step (2).

(5) Loading: calculate the corresponding torque, axial force, outer and inner pressure of the designed stress path; then input the parameters, together with the designed frequency and cycles under stress mode and start the test.

(6) Re-seepage test: correct the sample size, conduct the seepage test again. This step is to study the effect of stress path on permeability.

If the complex stress path or dynamic effect is not included, then only the first 3 steps are needed.

\subsection{Seepage stability standard}

\subsubsection{Seepage stability after static loading.}

With regard to seepage stability, ASTM D5084 specifies that when the ratio of inflow to outflow rate is between 0.75 and 1.25 [13], at the same time the permeability coefficient is stable and within $\pm 25 \%$ of the mean value, then the seepage flow can be considered as stable. Chapuis used the rigid wall device to study the seepage characteristic of silt soil and pointed out that the seepage can be regarded as stable when both the inflow velocity difference and the outflow velocity difference not exceeding 1\% [14]. Thus, different test devices and soils have different seepage standards for stability. For HCA seepage test, seepage stable stage needs to be studied to guarantee the reliability of calculated permeability. First taking 3600 seconds (1 hour) as unit time, calculate the relative flow difference and the permeability coefficient per unit time, which is shown in Table 3.

Fig. 1 shows the relative flow difference curve over time, and Fig. 2 is the measured permeability coefficient curve. Combining these two figures, it can be observed that the relative flow difference is initially large but gradually stabilizes to a certain extent. However, if the seepage stability is determined according to the flow ratio of D5084, that is, 0.75 to 1.25 , then the sample can be considered to enter the stable seepage state at the very beginning. However, the maximum value of the measured permeability coefficient is $14.72 \times 10-7 \mathrm{~cm} / \mathrm{s}$, which is $11 \%$ higher than the minimum value of $13.27 \times 10-7 \mathrm{~cm} / \mathrm{s}$, and the fluctuation is large. 
Table 3. Relative flow difference and average permeability coefficient in S1i10 test per unit time

\begin{tabular}{ccccccccc}
\hline Time $/ h$ & $\begin{array}{c}\text { Relative } \\
\text { flow } \\
\text { difference/ } \%\end{array}$ & $\begin{array}{c}k / \times 10^{-7} \\
\mathrm{~cm} / \mathrm{s})\end{array}$ & Time $/ h$ & $\begin{array}{c}\text { Relative } \\
\text { flow } \\
\text { difference/\% } / \%\end{array}$ & $\begin{array}{c}k / \times 10^{-7} \\
\mathrm{~cm} / \mathrm{s})\end{array}$ & Time $/ h$ & $\begin{array}{c}\text { Relative } \\
\text { flow } \\
\text { difference/\% } / \%\end{array}$ & $\begin{array}{c}k / \times 10^{-7} \\
\mathrm{~cm} / \mathrm{s})\end{array}$ \\
\hline 1 & -17.08 & 14.72 & 18 & -0.62 & 13.37 & 35 & 0.21 & 13.69 \\
2 & 1.85 & 13.71 & 19 & -0.62 & 13.49 & 36 & 4.42 & 13.51 \\
3 & -3.17 & 13.79 & 20 & -1.87 & 13.27 & 37 & -1.12 & 13.60 \\
4 & -1.91 & 13.70 & 21 & -2.04 & 13.44 & 38 & -1.32 & 13.53 \\
5 & -0.61 & 13.76 & 22 & -0.62 & 13.49 & 39 & -0.51 & 13.63 \\
6 & -0.21 & 13.79 & 23 & 2.46 & 13.71 & 40 & -2.13 & 13.57 \\
7 & 0.21 & 13.66 & 24 & -0.91 & 13.65 & 41 & -2.64 & 13.51 \\
8 & -1.93 & 13.53 & 25 & -0.31 & 13.63 & 42 & -1.43 & 13.56 \\
9 & -1.12 & 13.58 & 26 & -0.41 & 13.65 & 43 & -0.72 & 13.57 \\
10 & 0.21 & 13.62 & 27 & -0.91 & 13.65 & 44 & -0.51 & 13.57 \\
11 & -0.51 & 13.50 & 28 & -1.52 & 13.63 & 45 & -0.31 & 13.48 \\
12 & -1.33 & 13.50 & 29 & -1.32 & 13.60 & 46 & -2.13 & 13.57 \\
13 & -0.82 & 13.53 & 30 & -1.61 & 13.69 & 47 & -0.51 & 13.50 \\
14 & -0.62 & 13.51 & 31 & -0.82 & 13.56 & 48 & -0.41 & 13.62 \\
15 & -1.13 & 13.48 & 32 & -2.53 & 13.55 & 49 & -0.92 & 13.52 \\
16 & -2.67 & 13.37 & 33 & -2.43 & 13.56 & 50 & 0.21 & 13.56 \\
17 & -0.92 & 13.43 & 34 & -0.31 & 13.57 & 51 & 2.80 & 13.60 \\
\hline
\end{tabular}

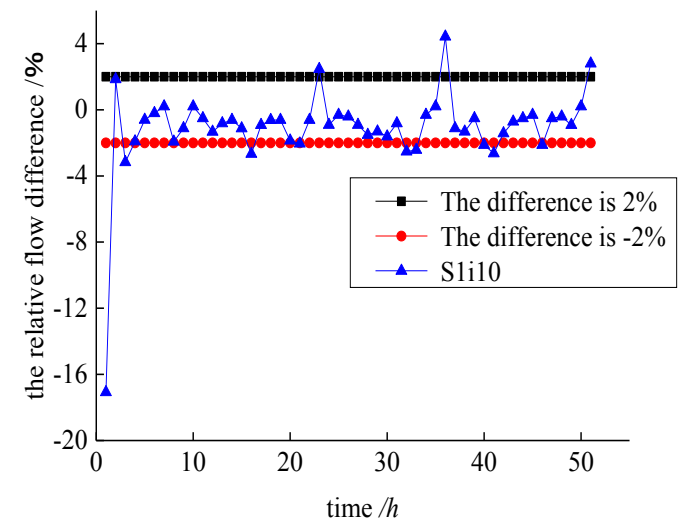

Fig. 1. The relative flow difference of S1i10

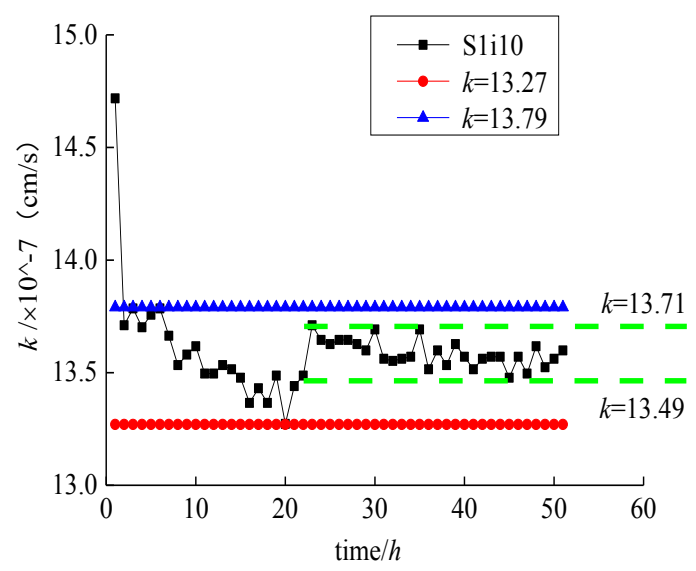

Fig. 2. Variation of permeability coefficient of S1i10

From Fig.1, it can be found that the relative flow difference will be stable within $2 \%$, but there are still big jumps in some time periods, such as 36th hour. This is mainly due to the soil consolidation during the seepage process, which relatively takes longer time. If taking the relative flow difference less than $2 \%$ as the seepage stability criterion, the maximum permeability coefficient measured in this interval is $13.79 \times 10^{-7} \mathrm{~cm} / \mathrm{s}$, which is about $4 \%$ higher than the minimum value of $13.27 \times 10^{-}$ ${ }^{7} \mathrm{~cm} / \mathrm{s}$. Since the anisotropy ratio of permeability coefficient is usually less than $1.6,4 \%$ in permeability coefficient will bring a great influence on permeability coefficient anisotropy. Therefore, only taking the relative flow difference as the seepage stability criterion in clay is not very convincing.

From Fig.2, it can be found that the fluctuation range of the permeability coefficient decreases further after $22 \mathrm{~h}$, and the maximum value $\left(13.71 \times 10^{-7} \mathrm{~cm} / \mathrm{s}\right)$ is only $2 \%$ higher than the minimum value $\left(13.49 \times 10^{-7} \mathrm{~cm} / \mathrm{s}\right)$, at the same time there is no obvious fluctuation in the following time. Considering the test efficiency and result accuracy, when the difference in average permeability coefficient within unit time (3600 seconds) less than $2 \%$ in continuous $24 \mathrm{~h}$, and the permeability coefficient in each unit time has no obvious increasing or decreasing tendency, this stage can be defined as the stage of seepage stability, and average permeability coefficient in this period can be taken as the ultimate permeability coefficient. According to this standard, the obtained permeability coefficient of S1i10 is $13.58 \times 10^{-7} \mathrm{~cm} / \mathrm{s}$.

\subsubsection{Seepage stability after dynamic loading}

Similar to the previous discussion, 3600s is taken as the unit time to calculate the relative flow difference and permeability coefficient per unit time of S2i10. The results are shown in Table 4. 
Table 4. Relative flow difference and average permeability coefficient in S2i10 test per unit time

\begin{tabular}{|c|c|c|c|c|c|c|c|c|}
\hline Time/h & $\begin{array}{c}\text { Relative } \\
\text { flow } \\
\text { difference/ } \\
\%\end{array}$ & $\begin{array}{c}k / \times 10^{-7} \\
(\mathrm{~cm} / \mathrm{s} \\
)\end{array}$ & Time $/ h$ & $\begin{array}{c}\text { Relative } \\
\text { flow } \\
\text { difference/ } \\
\%\end{array}$ & $\begin{array}{c}\mathrm{k} / \times 10^{-7} \\
(\mathrm{~cm} / \mathrm{s} \\
)\end{array}$ & Time $/ h$ & $\begin{array}{c}\text { Relative } \\
\text { flow } \\
\text { difference/ } \\
\%\end{array}$ & $\begin{array}{c}k / \times 10^{-7} \\
(\mathrm{~cm} / \mathrm{s} \\
\quad)\end{array}$ \\
\hline 1 & -63.07 & 9.66 & 31 & 14.35 & 9.73 & 61 & 14.8 & 9.36 \\
\hline 2 & 24.64 & 9.54 & 32 & 11.98 & 9.68 & 62 & 11.92 & 9.27 \\
\hline 3 & 28.92 & 10.03 & 33 & 14.66 & 9.78 & 63 & 13.18 & 9.33 \\
\hline 4 & 30.62 & 9.99 & 34 & 9.08 & 9.67 & 64 & 9.11 & 9.12 \\
\hline 5 & 26.21 & 10.21 & 35 & 13.53 & 9.72 & 65 & 16.34 & 9.4 \\
\hline 6 & 19.45 & 9.89 & 36 & 10.89 & 9.53 & 66 & 5.76 & 8.96 \\
\hline 7 & 14.61 & 9.81 & 37 & 9.65 & 9.77 & 67 & 11.85 & 9.2 \\
\hline 8 & 13.96 & 9.79 & 38 & 13.78 & 9.65 & 68 & 9.86 & 9.09 \\
\hline 9 & 14.49 & 9.84 & 39 & 15.68 & 9.73 & 69 & 11.26 & 9.11 \\
\hline 10 & 15.28 & 9.92 & 40 & 11.87 & 9.65 & 70 & 10.73 & 9.09 \\
\hline 11 & 15.42 & 9.92 & 41 & 11.09 & 9.61 & 71 & 8.09 & 8.97 \\
\hline 12 & 13.73 & 9.94 & 42 & 10.89 & 9.52 & 72 & 12.24 & 9.15 \\
\hline 13 & 17.35 & 10.08 & 43 & 12.74 & 9.58 & 73 & 13.89 & 9.13 \\
\hline 14 & 14.88 & 9.79 & 44 & 12.98 & 9.57 & 74 & 16.37 & 9.04 \\
\hline 15 & 14.26 & 9.94 & 45 & 12.87 & 9.54 & 75 & 15.66 & 9.06 \\
\hline 16 & 12.38 & 9.84 & 46 & 10.93 & 9.43 & 76 & 13.2 & 9.21 \\
\hline 17 & 13.77 & 10.01 & 47 & 11.76 & 9.38 & 77 & 12.4 & 9.03 \\
\hline 18 & 7.97 & 9.69 & 48 & 15.64 & 9.61 & 78 & 16.4 & 9.12 \\
\hline 19 & 11.49 & 9.78 & 49 & 6.30 & 9.17 & 79 & 15.9 & 9.03 \\
\hline 20 & 12.94 & 9.87 & 50 & 14.03 & 9.29 & 80 & 13.2 & 9.35 \\
\hline 21 & 10.25 & 9.69 & 51 & 14.63 & 9.32 & 81 & 17 & 9.27 \\
\hline 22 & 13.61 & 9.82 & 52 & 16.51 & 9.23 & 82 & 13.5 & 9.36 \\
\hline 23 & 12.90 & 9.79 & 53 & 22.38 & 9.39 & 83 & 14.5 & 9.2 \\
\hline 24 & 13.39 & 9.76 & 54 & 14.47 & 9.22 & 84 & 12.3 & 9.15 \\
\hline 25 & 16.25 & 9.76 & 55 & 14.49 & 9.31 & 85 & 12.6 & 9.38 \\
\hline 26 & 15.11 & 9.69 & 56 & 14.77 & 9.33 & 86 & 13.5 & 9.14 \\
\hline 27 & 18.49 & 9.78 & 57 & 11.00 & 9.31 & 87 & 15.6 & 9.02 \\
\hline 28 & 15.97 & 9.70 & 58 & 12.67 & 9.35 & 88 & 11.3 & 9.05 \\
\hline 29 & 19.62 & 9.81 & 59 & 12.96 & 9.37 & 89 & 10.5 & 9.24 \\
\hline 30 & 13.36 & 9.63 & 60 & 12.39 & 9.38 & 90 & 11.4 & 9.36 \\
\hline
\end{tabular}

Different from the seepage test after static loading, the fluctuation range of the relative flow difference is much greater, seen in Fig.3. Except for the huge difference (more than 20\%) within the first 6 hours, the relative flow difference gradually stabilize at the range between $10 \%$ $20 \%$. But according to the D5084, the sample can be considered to enter the stable seepage state at the very beginning. However, the maximum value of the measured permeability coefficient is $10.08 \times 10^{-7} \mathrm{~cm} / \mathrm{s}$, which is $12.5 \%$ higher than the minimum value of $8.96 \times 10^{-7} \mathrm{~cm} / \mathrm{s}$, and the fluctuation is large.

According to the seepage stability criterion after static loading, permeability coefficient is an important parameter and needs to be considered in seepage stability criterion. As shown in Fig.4, different from the test after static loading, the permeability coefficient after dynamic loading has downward fluctuation. That's the consequences of particle rearrangement during dynamic loading and alignment after water flow. During the whole seepage process, it can be found that the permeability coefficient is relatively stable in two stages. The first stage is from $21 \mathrm{~h}$ to $45 \mathrm{~h}$, the maximum permeability coefficient is $9.82 \times 10-7 \mathrm{~cm} / \mathrm{s}$, which is $3.2 \%$ higher than the minimum value of $9.52 \times 10-7 \mathrm{~cm} / \mathrm{s}$. The second stage is from $51 \mathrm{~h}$ to $75 \mathrm{~h}$, the maximum permeability coefficient is $9.4 \times 10-7 \mathrm{~cm} / \mathrm{s}$, which is $5 \%$ higher than the minimum value of $8.96 \times 10-7 \mathrm{~cm} / \mathrm{s}$. If the former stage is defined as the seepage stable stage, the permeability coefficient will also have great fluctuation in the following time, as shown in Fig.4. While if the latter defined as the seepage stable stage, there will be no obvious fluctuation in the following time.

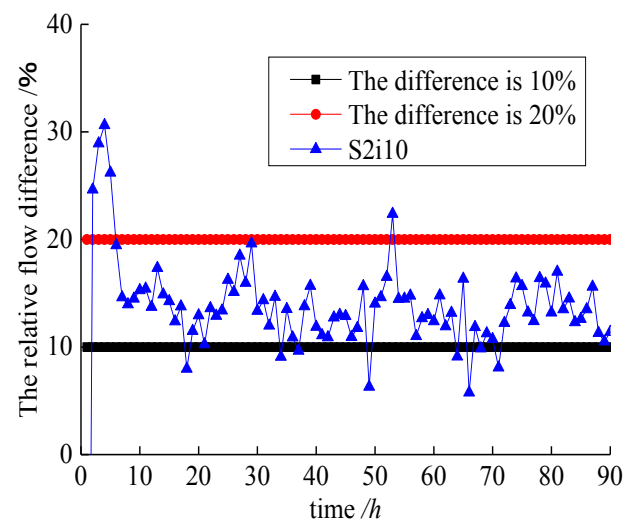

Fig. 3. The relative flow difference of S2i10

\footnotetext{
* Corresponding author: zjelim@,zju.edu.cn
} 


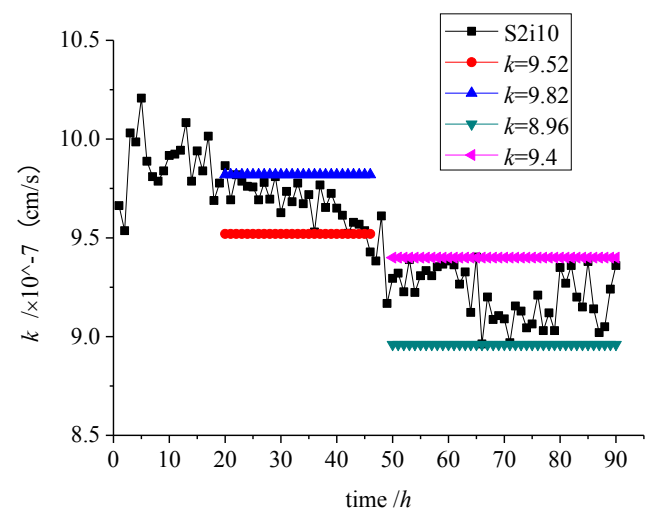

Fig. 4. Permeability coefficient curve of S2i10

So for seepage test after dynamic loading, when the difference in average permeability coefficient within unit time is less than $5 \%$ in continuous $24 \mathrm{~h}$, simultaneously the permeability coefficient has no obvious increasing or decreasing tendency, then the seepage can be considered stable. The average permeability coefficient in this period is the ultimate permeability coefficient. According to this standard, the obtained permeability of S2i10 in this test is $9.22 \times 10^{-7} \mathrm{~cm} / \mathrm{s}$.

\section{Conclusion}

In this paper, seepage test by proper ZJU-HCA is explored. With the discussion on seepage stable stage for static and dynamic loading, the following conclusions can be drawn as follows:

(1) In static seepage test, when the difference in average permeability coefficient within unit time (3600 seconds) is less than $2 \%$ in continuous $24 \mathrm{~h}$, it is reliable to take the average permeability coefficient in this period as the ultimate permeability;

(2) However, in dynamic seepage test, if the difference of permeability coefficient is less than $5 \%$ in continuous $24 \mathrm{~h}$, simultaneously the permeability coefficient has no obvious increasing or decreasing tendency, the average permeability coefficient in this period can be taken as the ultimate permeability coefficient. Since the dissipation of excess pore water pressure will enlarge the difference between the back pressure and base pressure, it takes longer time to approach the stable state.

This study is supported by the National Key R\&D Program of China (2016YFC0800203) and Natural Science Foundation of China (Grant 51338009 and 511784222). Their supports are gratefully acknowledged.

\section{References}

1. G. Y. Liu, Engineering Investigation, 2 (1997)

2. T. S. Nagaraj, Geotechnique, 44(2) (1994)

3. J. J. Bowders Jr, D. E. Daniel, Journal of Geotechnical Engineering, 113(12) (1987)

4. W. B. Cao, K. W. Li, Y. L. Liu, Hydrogeology and Engineering Geology, 4 (1986)
5. Y. L. Du, C. H. Li, J. H. Xu, Journal of Hydraulic Engineering, 4 (1980)

6. H. Ke, W. F. Wang, Journal of Zhejiang University (Engineering Science), 47(7) (2013)

7. G. L. Zhang, Y. J. Wang, Rock and Soil Mechanics, 10 (2014)

8. K. H. Xie, Y. C. Zhuang, X. B. Li, Chinese Journal of Geotechnical Engineering, 27(05) (2005)

9. X. Hao, Zhejiang University, 2016.

10. L. R. Kong, Chinese Journal of Underground Space and Engineering, 7(S2) (2011)

11. S. Horpibulsuk, N. Yangsukkaseam, A. Chinkulkijniwat, Y. J. Du, Applied Clay Science, 52(1-2) (2011)

12. L. G. Yu, J. Zhou, X. G. Wen, J. Xu, L. H. Luo, Rock and Soil Mechanics. (to be published)

13. ASTM D5084-16a, ASTM, 2016

14. R. P. Chapuis, M. Aubertin, Can Geotech J, 27(3) (2004) 